\title{
Compensatory Eating Behaviors, Alcohol Consumption and Opioid Use in a Clinical Sample
}

\author{
Beau J. Diehl ${ }^{1}$ \\ ${ }^{1}$ Department of Humanities and Social Sciences, Grand Canyon University, Phoenix, Arizona, United States \\ Correspondence: Beau J. Diehl, Department of Humanities and Social Sciences, Grand Canyon University, Phoenix, \\ Arizona, United States.
}

Received: March 20, 2017

doi:10.11114/ijsss.v5i5.2376
Accepted: April 19,2017 Available online: April 24, 2017

URL: https://doi.org/10.11114/ijsss.v5i5.2376

\begin{abstract}
Objectives: To estimate the prevalence of compensatory eating behaviors in relation to alcohol consumption in a clinical sample, to assess the moderating capabilities of opioid use in relation to alcohol use and compensatory behaviors, and to examine the predictive capabilities of gender-specific binge drinking in relation to compensatory behaviors.
\end{abstract}

Methods: The Compensatory Eating Behaviors in Relation to Alcohol Consumption Scale (CEBRACS), an opioid use survey, and the Alcohol Use Disorders Identification Test (AUDIT) were administered to residents at an addiction treatment facility $(n=77)$ over a period of 6 months.

Results: Morphine was the only opioid to have significant relationships with the CEBRACS alcohol effects $(r=-.33)$, diet/exercise $(r=-.38)$, and restrictive eating $(r=-.31)$, subscales (all $p<.001)$, but not with the bulimic subscale. Heroin had the strongest correlations with all other opioids. Opioid use did not have a significant moderating effect between alcohol frequency and the CEBRACS in a single moderating regression analysis $(b=.84, t(73)=.43, p=.67)$. Men $(M d n$ $=27.00)$ and women $(M d n=33.00)$ did not differ on the CEBRACS, although women ranked higher than men $(U=$ $678.00, z=-.68, n s, r=.08)$. Binge drinking predicted CEBRACS scores in both males $(b=.50, t(38)=3.59, p<.001)$ and females $(b=.60, t(35)=4.46, p<.001)$.

Conclusions: Individual dietary habits fluctuate throughout alcohol consumption and the goals of the individual are crucial in discerning specific substance use vs disordered eating motivations.

Keywords: compensatory eating behaviors in relation to alcohol consumption scale, opioid use, substance use disorders, eating disorders, body dysmorphic disorders, alcohol use disorders

\section{Introduction}

Substance use disorders can be extremely deleterious to a person's physical and psychological health, compromise a person's standing within the context of vocation and/or academia, result in a breakdown of interpersonal relationships between friends and family, and potentially lead to suicide and death (American Psychiatric Association [APA], 2013; Centers for Behavioral Health Statistics and Quality [CBHSQ], 2015). Specifically, alcohol and opioid use disorders are of particular detriment to individuals as well as American society, as alcohol use disorder prevalence is at 16.3 million adults (1.3 million men and 5.7 million women), and opioid use disorder prevalence stakes 1.9 million for prescription drugs and 586,000 for heroin as of 2014 (Substance Abuse and Mental Health Services Administration [S AMSHA], 2014; CBHSQ, 2015). Alcohol-related deaths were believed to average 88,000 between 2006 and 2010, rendering it as the fourth leading preventable cause of death in the United States (Centers for Disease Control and Prevention [CDC], 2013). Alcohol abuse has been found to have detrimental biophysical effects including death, brain damage, cardiovascular, liver, and pancreatic disease as well as cancer proximal to the esophagus, larynx, mouth, colon, and breasts (see Anderson, Cremona, Paton, Turner, \& Wallace, 1993; Shield, Parry, \& Rehm, 2013).

Opioid use disorder can produce extremely negative outcomes for individuals and society. Opioid overdoses are responsible for killing over 28,000 people in 2014, and since 1999 opioid overdose rates have drastically increased for both men (265\%) and women (400\%) over the past 17 years (CDC, 2016). Opioid abuse has been hailed as an epidemic by the CDC, and can have negati ve biophysical effects including brain damage, depressed respiration (hypoxia), seizures, liver and kidney damage, coma, and death (see Hart \& Ksir, 2012). 
Alcohol and opioid abuse maintain the propensity for harmful environmental, psychological, and physical detriments, but the negative effects for both of these substance use disorders can be greatly exacerbated when they co-occur with other ailments such as eating disorders (Franko et al., 2013). Eating disorders such as anorexia and bulimia nervosa have been well-documented to frequently co-occur with alcohol use disorder, and these co-occurrences can make efficacious diagnostic and intervention methods markedly difficult for clinicians (Centers on Addiction and Substance Abuse [CASA], 2003). Furthermore, the specific amalgam of eating and substance use disorders is often accompanied by some type of comorbidity such as anxiety, depressive, or personality disorder which further complicates the diagnostic process (Bulik et al., 2004). This complication is highly problematic, and a better examination of the interrelationships between opioid use, alcohol use, and eating disorders is necessary to identify characteristics which may be unique to specific combinations of substance use and eating disorders.

\section{Alcohol Use Disorder and Disordered Eating}

Women have been identified as an at-risk population for experiencing negative biophysical effects of alcohol including: (a) increased brain damage resulting from alcohol (ab)use, (b) a proneness to thiamine deficiencies, (c) a higher likelihood of developing cirrhosis, (d) a higher risk for acute alcohol intoxication leading to toxicity, (e) an increased risk of developing hormonal disorders, (f) and an increased probability of engaging in sexually risky behavior and contracting sexually transmitted diseases (CASA, 2003; Mancinelli, 2013; National Institute on Alcohol Abuse and Alcoholism [NIAAA], 1993). Limited research has addressed the activity of engaging in disordered eating patterns in relation to consuming alcohol, and a further examination of disordered eating in concurrence with alcohol consumption may support a recently submitted ailment coined "drunkorexia" (Chambers, 2008; Eisenberg \& Fitz, 2014; Kershaw, 2008). The crude term of "drunkorexia" simply describes the behavior of replacing meals with alcohol, but this observed phenomenon may have greater underlying body image disturbance, body dysmorphic, and substance use correlates than putatively believed.

It is likely that the concomitance of alcohol use and eating disorders maintain a very important temporal characteristic. To explain, the phenomenon of engaging in disordered eating prior to, during, and/or after imbibing alcohol may be indicative of the goals of the imbiber, whether they are ultimately pursuant to body image or expediting the effects of alcohol (see Peralta, 2002). Discerning if a person engages in caloric restriction, for example, before consuming alcohol as a means to quickly experience inebriation rather than compensate for the calories in alcohol is an important contrast demarcating the influence of alcohol use versus the influence of an eating disorder. Importantly, the risks of intoxication are often exacerbated through dietary modification in relation to alcohol (ab)use, and the way in which a person consumes nutrition in relation to alcohol consumption has a direct effect on the intensity and potentially hazardous effects of the alcohol consumed (Burke et al., 2010).

Correlations between alcohol use disorder and disordered eating have been consistently established in the extant literature for both females (e.g. Fischer, Settles, Collins, Gunn, \& Smith, 2012; Ortega, Chapela, \& Santoncini, 2012) as well as males (e.g. Burke, Cremeens, Vail-Smith, \& Woolsey, 2010; Dierks, 2014). Caloric restriction in anticipation of drinking has been linked to a number of hazardous behaviors across gender. For example, Giles, Champion, Sutfin, McCoy, \& Wagoner (2009) reported that 39\% ( $n=4,271)$ of college students throughout 10 universities admitted to restricting calories before alcohol consumption. They also found that males who restricted calories and drank were $82 \%$ more likely to engage in a physical fight and that females who restricted calories and drank were more likely to be hurt or injured, sexually exploited, suffer from memory loss, and engage in unprotected sex.

The findings from Giles et al., (2009) indicated that caloric restriction before consuming alcohol can have serious detrimental effects, especially for men, as male participants' odds of getting drunk were $99 \%$ higher when compared to male "non-restrictors" in the study ( $\mathrm{AOR}=1.99,[95 \% \mathrm{CI}=1.48-2.68])$. This finding is salient in how it may relate to female alcohol (ab) use and the disparity between the effects of alcohol with regard to gender. Historically, women tend to experience exacerbated effects from alcohol when compared to men. This is primarily due to biological differences with results indicative of poorer cognitive and behavioral functions and "telescoping" effects through increased mortality and morbidity in a shorter time and from less alcohol consumption than men (Mancinelli, 2013). Therefore, it is a concern that men who engage in caloric restriction prior to alcohol use may negate certain biological characteristics that help to diminish the telescopic effects of alcohol use identified in women; and so men who engage in disordered eating before imbibing may be at a comparable if not greater risk for the similar negative outcomes consequent of alcohol (ab)use associated with women who do not restrict. Similarly, women who restrict calories prior to drinking would then be at an even greater risk for negative consequences associated with over-intoxication. Thus, caloric restriction in relation to alcohol consumption can be viewed as a serious and potentially deadly problem for both sexes.

Succinctly, the importance of such findings indicate that alcohol (ab) use can be harmful for both males and females. Regardless of gender, consuming alcohol on an empty stomach will lead to a faster metabolization of alcohol and therefore raise blood alcohol levels faster which increases the likelihood of memory impairment, blackout, and negative effects 
consequential of rapid alcohol use in both males and females (White, 2004). Typically, research has shown that the quality of a person's diet worsens as their alcohol intake increases (NIAAA, 1993). Specifically, many moderate-to-heavy drinkers suffer from primary (i.e. alcohol replaces other nutrients within a diet) and secondary (i.e. alcohol interferes with the pro per absorption of nutrients in the body) forms of malnutrition, resulting in vitamin deficiencies, complications with digesting carbohydrates and proteins, oxidative stress, and impaired liver function (Lieber, 1991; Lieber, 2003). Because many alcohol abusers do not intake proper nutrients prior to imbibing, the detriments of malnutrition are often exacerbated by alcohol's negative effect on the body's ability to process such nutrients, which further illustrates the unhealthy and likely maladaptive relationship between caloric restriction and alcohol (ab) use.

\section{Opioid Use, Di sordered Eating, and Alcohol Use as Co-occurring Disorders}

The National Institute on Drug Abuse (NIDA) defined opioids as medications that attach to specific opioid receptors throughout the body with the intended result of diminishing experienced pain signals to the brain (NIDA, 2014). Common types of opioids include fentanyl, oxycodone, hydrocodone, hydromorphone, morphine, methadone, and heroin. Although opioid treatments have proved to be effective pharmacological analgesics for individuals suffering from both malignant and non-malignant pain, many individuals develop opioid addictions that can result in a slowing of gastrointestinal activity, decreases in gut motility, hypoxia, brain damage, and death (APA, 2013; CBHSQ, 2015). The Substance Abuse and Mental Health Services Administration (SAMHSA) indicated in their Treatment Episodes Data Set (TEDS) that the number of patients who were admitted to addiction treatment facilities due to non-heroin related opioid misuse rose from 23,000 to over 90,000 from 1999 to 2007 (SAMHSA, 2007). Societally, prescription opioid abuse was estimated to cost the United States 55.7 billion dollars across criminal justice (9\%), workplace (46\%), and health care (45\%) arenas (Birnbaum et al. 2011). Therefore, longitudinal as well as meta-research has shown that opioid addiction is a growing problem with severe societal detriments.

Psychologically, alcohol and opioid dual addiction has been correlated with several psychopathologic ailments broadly including schizophrenic and neurotic behavior, mood disorders, major depressive disorder, generalized anxiety disorder, and bipolar disorder (Martins et al. 2012). Biologically, alcohol and opioids are both classified as depressants and their concurrent use can have debilitating as well as terminating effects on central nervous system function (Hart \& Ksir, 2012). Fleming, Balousek, Klessig, Mundt \& Brown (2007) found that $36 \%$ of daily opioid users reported that they had at least one drink within the past 30 days. Saunders et al., (1993) reported that one in eight participants admitted to having two or more drinks within two hours of taking an opioid $(n=1,848)$. It is possible that the concurrent use and/or abuse of alcohol and opioids are contributive to opioid-related overdoses rising from 4,000 to over 13,800 from 1999 to 2006 (Warner, Chen \& Makuc, 2009) and severely increasing for both men (265\%) and women (400\%) throughout 1999 to 2016 (CDC, 2016).

Specific, widespread data on individuals who engage in disordered eating, opioid (ab)use, and alcohol (ab)use are not known, but the biophysical similarities pertaining to the ways in which each of these factors affect the body has been well-established. Alcohol use, opioid use, and food consumption are interrelated insofar as they each produce reward qualities within the brain and have been shown to be related to the production of endorphins (Gosnell \& Levine, 2009; Herz, 1997; Krahn et al. 2005). This, in part, explains why food, opioids, and alcohol maintain addictive characteristics. There is also reason to believe that disordered eating, alcohol use, and opioid use are compatible as co-occurring disorders. According to Herz (1997) food intake, alcohol consumption, and opioid use affect the same types of opioid receptors (mu, delta, and kappa) and therefore affect the same endogenous opioid peptides (beta-endorphin, enkephalins and dynorphins). However, alcohol has been shown to slow do wn the metabolism of opioids such as a methadone, and disruptions in opioid metabolic rates may influence biological dependence and therefore fuel a type of dual addiction with regard to alcohol and opioids (Islam, Day, Conigrave, \& Topp, 2013).

As mentioned, many individuals report caloric restriction resultant from alcohol consumption either influenced by a preliminary conscientiousness of the intake of empty calories or an experienced feeling of satiation from consuming the empty calories within alcohol. Mercer and Holder (1997) have identified that food intake is also influenced by these same endogenous opioid peptides and similar feelings of reward. In relation to the use of psychoactive substances, Carr (2002) had found that chronic food restriction augments the rewarding effect of many abused drugs and further supports the documented co-occurrence of drug abuse and eating disorders. In other words, individuals have an incentive to restrict food in conjunction with the use of other drugs and alcohol because the experienced reward and psychoactive effects are intensified under caloric-restricted conditions. Adopting a centralized body image disturbance lens, it is reasonable to hypothesize that individuals who engage in disordered eating do so to offset the calories within alcohol, and they may also engage in such behaviors as a means to enhance the effects of opioids and/or alcohol. Augmentation of the reward sensation of these two psychoactive substances may also serve as positive reinforcement for these individuals whereby they continue to restrict calories in an attempt to control their weight and also enhance the effects of opioids and alcohol. This behavior may be further influenced by the frequency with which individuals imbibe and their tolerance to alcohol and opioids collectively. 
The purposes of this study are to: (a) explore possible relationships between opioid use, alcohol use, and compensatory eating behaviors, (b) assess if opioid use moderates a relationship between the frequency of alcohol use and compensatory eating behaviors in relation to alcohol consumption, (c) examine gender differences with regard to compensatory eating behaviors in relation to alcohol consumption, and (d) use the CEBRACS in a clinical sample.

\section{Hypotheses}

1. There is a significant, positive relationship between opioid use, alcohol use, and compensatory eating behaviors in relation to alcohol consumption.

2. Opioid use will moderate the relationship between the frequency of alcohol use and compensatory eating behaviors in relation to alcohol consumption.

3. Women will exhibit more compensatory eating behaviors in relation to alcohol consumption than men.

4. Binge drinking will predict compensatory eating behaviors in relation to alcohol consumption across both genders.

\section{Materials and Method}

\subsection{Participants}

Participants consisted of both males and females who were inpatient residents at an addiction management clinic in the Midwest. Permission to conduct the study was acquired from both the clinic as well an ethics committee. A series of invitational presentations at both male and female facilities occurred over the course of six months. A total of 77 questionnaires were returned and collected after the six month collection period.

\subsection{Instruments}

Demographic Questionnaire. A demographic questionnaire was administered to participants. This questionnaire included the items of sex, age, race, opioid use (dichotomously framed), and types of opioids used within the past year. The types of opioids used are based on common substances identified by SAMSHA (2007) and include: fentanyl, hydrocodone, hydromorphone, methadone, morphine, oxycodone, heroin, and meperidine.

The Compensatory Eating Behaviors in Response to Alcohol Consumption Scale (CEBRACS). The CEBRACS (Rahal, et al. 2012) is a 21-item measure intended to assess behaviors associated with controlling calories in relation to alcohol consumption as well as controlling calories as a means to intensify the effects of alcohol. The CEBRACS is structured via a 5-point Likert-type scale where respondents are asked to comment on their behaviors ranging from 1 (Never) to 5 (Almost all the time). The measure is comprised of four factors: Alcohol Effects, Bulimia, Diet and Exercise, and Restriction. To date, the CEBRACS is the only quantitative measure intended to assess caloric control and alcohol use with the inclusion of a temporal characteristic, meaning that the CEBRACS asks participants to report on their behaviors prior to, during, and after drinking alcohol.

The CEBRACS was standardized in a sample of undergraduate students (51 males and 233 females). The collective Cronbach's alpha level for the scale was $\alpha=.89$, with each of the subscales ranging from $\alpha=.79-.95$. The CEBRACS also exhibited adequate convergent validity with small to medium correlational effect sizes for a drive for thinness, body dissatisfaction, and bulimic behaviors (Rahal, et al. 2012). The CEBRACS demonstrated sufficient discriminant validity through a nonsignificant relationship with the Global Belief in a Just World Scale (Lipkus, 1991).

The Alcohol Use Disorders Identification Test (AUDIT). The Alcohol Use Disorders Identification Test (AUDIT) from Saunders, Aasland, Babor, De la Fuente, \& Grant (1993) is a 10-item instrument with three subscales intended to assess: (a) drinking frequency, (b) drinking dependence, and (c) alcohol-related problems. The AUDIT has been validated in patients across six countries, and is one of the few alcohol screening assessment designed for international use (Babor, Higgins-Biddle, Saunders, \& Monteiro 2001). The measure is structured through Likert-type scaling where the first eight items are on a 5-point scale where responses are 0 (Never) to 4 (Daily/Almost Daily), and the last two questions related to hazardous/problematic drinking are rated on a 3-point scale where responses are 0 (No), 2 (Yes, but not in the past year), and 4 (Yes, during the past year).

Total scores of eight or more on the AUDIT are indicative of hazardous and harmful alcohol use and possible alcohol dependence (Babor, et al., 2001). The AUDIT has proved to be more robust at differentiating between hazardous versus nonhazardous drinkers as well as harmful versus nonharmful drinkers than the Michigan Alcoholism Screening Test (MAST) in previous research (see Bohn, Babor, \& Kranzler, 1995). The AUDIT has demonstrated good scores of reliability and validity with test-retest results $(r=.86)$ and an adequate Cronbach's alpha level of $\alpha=.80$ (Allen, Litten, Fertig, \& Babor, 1997; Rumpf, Hapke, Meyer, \& John, 2002). The AUDIT $(\alpha=.92)$ and the CEBRACS $(\alpha=.96)$ each had excellent internal consistencies within the current study. 


\subsection{Data Analysis}

Data were analyzed using SPSS version v. 21 . The 77 participants were screened for missing items and outliers. An analysis of monotonicity indicated that only $1.43 \%$ of values were missing from the study and that a majority of missing items were contained within the CEBRACS portion of the questionnaire. It was desirable to retain all cases within the study, and therefore mean series replacement was used to correct for missing items as this method has proved to be effective in instances where less than 5\% of the total values are missing (Parent, 2012). These procedures resulted in a final sample size of 77 .

All variables displayed a bimodal distribution and were clearly non-normally distributed. A non-normal distribution was statistically supported by a series of Kolmogorov-Smirnov, Lilliefores corrections and Shaprio-Wilk tests $(p<.001)$. The nonormality of the data was likely attributable to all variables within the study maintaining categorical scaling except for the variable of age. Therefore, nonparametric testing was used in lieu of data transformation to preserve meaningful information (Jamieson, 2004).

\section{Results}

\subsection{Demographic Information}

There were $40(51.9 \%)$ men and 37 women $(48.1 \%)$ in the final sample of participants. Ages ranged from 18 to $60(M=$ 35.10, $S D=10.30$ ). Most participants $(87 \%)$ identified as European American-Caucasian, followed by Other $(5.2 \%)$, American Indian/Native American (3.9\%), Black/African American (1.3\%), Asian/Pacific Islander (1.3\%), and Biracial/Multiracial (1.3\%). A majority of participants reported a relational status of single $(53.2 \%)$, followed by divorced (27.3\%), married (10.4\%), partnered (3.9\%), engaged (2.6\%), and cohabitating (2.6\%). Participants commonly identified as being heterosexual (87\%), followed by bisexual (10.4\%) and gay (2.6\%).

\subsection{Opioid and Alcohol Prevalence}

More than half of the participants (68\%) reported taking some type of opioid within the last year (29 women and 24 men). Hydrocodone, morphine, and oxycodone were reported as the most common substances used by the sample. Meperdine and fentanyl were the least commonly used opioids (see Table 1). Among the 52 individuals who reported opioid use within the last year, only seven $(13.50 \%)$ reported never consuming alcohol with any regularity, and 20 (38.46\%) opioid users indicated highly frequent (more than four times each month) alcohol use.

Table 1. Prevalence of Opioid Use Classified by Gender and Specific Drug-Type

\begin{tabular}{|c|c|c|c|c|c|}
\hline & Male Frequency & Male Percent & Female Frequency & Female Percent & $\begin{array}{r}\text { Total } \\
\text { Percen }\end{array}$ \\
\hline $\begin{array}{l}\text { 1. Fentanyl (e.g. Sublimaze, Actiq, } \\
\text { Duragesic, Fentora) }\end{array}$ & 11 & $14.3 \%$ & 10 & $13 \%$ & $27.3 \%$ \\
\hline 2. Hydrocodone (e.g., Vicodin, Lortab) & 21 & $27.3 \%$ & 22 & $28.6 \%$ & $55.8 \%$ \\
\hline 3. Hydromorphone (e.g. Dilaudid) & 14 & $18.2 \%$ & 17 & $22.1 \%$ & $40.3 \%$ \\
\hline $\begin{array}{l}\text { 4. Methadone (e.g. Methadose, } \\
\text { Dolophine) }\end{array}$ & 15 & $19.5 \%$ & 18 & $23.4 \%$ & $42.9 \%$ \\
\hline 5. Morphine (e.g., Kadian, Avinza) & 18 & $23.4 \%$ & 20 & $26 \%$ & $49.4 \%$ \\
\hline $\begin{array}{l}\text { 6. Oxycodone (e.g. OxyContin, } \\
\text { Percocet) }\end{array}$ & 16 & $21 \%$ & 22 & $28.6 \%$ & $49.4 \%$ \\
\hline $\begin{array}{l}\text { 7. Meperidine (e.g. Demerol and } \\
\text { Meperitab) }\end{array}$ & 6 & $7.8 \%$ & 4 & $5.2 \%$ & $13 \%$ \\
\hline 8. Heroin & 13 & $16.9 \%$ & 17 & $22.1 \%$ & $39 \%$ \\
\hline
\end{tabular}

A majority of the sample (89.6\%) indicated that they drank alcohol regularly, with slightly more men (51.9\%) than women $(48.1 \%)$ reporting alcohol use. Specifically, $45.5 \%$ of individuals reported that they drank four or more times each week. The frequency, dependence, and alcohol-related problem subscales of the AUDIT were specifically analyzed to ascertain which dimensions of alcohol use were salient problem areas for the sample. A total score of eight or more on the AUDIT is indicative of dangerous alcohol use (Babor, et al., 2001) and therefore a score of eight or more was used to confidently define dangerous drinking within each of the AUDIT subscales. Crosstabulation revealed that 43 individuals $(M=6.96 S D=4.30)$ displayed dangerous behaviors related to alcohol frequency; 42 individuals $(M=7.38$, $S D=5.86)$ displayed high levels of alcohol-related problems and 26 individuals $(M=4.99, S D=4.53)$ had scores indicative of high levels of alcohol dependence.

\section{Hypothesis 1}

Kendall's tau $b$ was used to generate a correlation matrix depicting the relationships between alcohol use, binge drinking, compensatory eating behaviors in relation to alcohol consumption, compensatory behaviors in relation to alcohol consumption before, during, and after consuming alcohol, and AUDIT and CEBRACS total scores. Drinking frequency, dependence, related problems, and male and female binge drinking were significantly related to the 
CEBRACS total scores and most of the CEBRACS subscales except for the bulimic behaviors subscale (see Table 2). Notably, male binge drinking was significantly related to bulimic behaviors while female binge drinking was not a significant correlate. AUDIT-measured behaviors maintained strong correlations with compensatory eating behaviors in relation to alcohol consumption both before and during consumption, but decreased markedly after imbibing.

Table 2. CEBRACS, AUDIT, and Binge Drinking Variables: Temporal and Gender-Specific Inclusions

\begin{tabular}{|c|c|c|c|c|c|c|}
\hline Variables & $\begin{array}{l}\text { AUDIT }^{\mathrm{b}} \text { : } \\
\text { Frequency }\end{array}$ & $\begin{array}{c}\text { AUDIT: } \\
\text { Dependence }\end{array}$ & $\begin{array}{l}\text { AUDIT: } \\
\text { Problems }\end{array}$ & $\begin{array}{l}\text { AUDIT: Total } \\
\text { Score }\end{array}$ & $\begin{array}{c}\text { Binge Drinking: } \\
\text { Male }\end{array}$ & $\begin{array}{l}\text { Binge Drinking: } \\
\text { Female }\end{array}$ \\
\hline 1. CEBRACS ${ }^{\mathrm{a}}$ : Effects & $.51^{* *}$ & $.30 * *$ & $.55^{* * *}$ & $.58^{* *}$ & $.54 * *$ & $.61 * *$ \\
\hline $\begin{array}{l}\text { 2. CEBRACS: Diet \& } \\
\text { Exercise }\end{array}$ & $.35^{* *}$ & $.31 * *$ & $.34 * *$ & $.36^{* *}$ & $.35^{* *}$ & $.40 * *$ \\
\hline 3. CEBRACS: Bulimia & $.19^{* * *}$ & .10 & $.29 * *$ & $.26 * *$ & $.28^{*}$ & .17 \\
\hline 4. CEBRACS: Restriction & $.38^{* * *}$ & .29 ** & $.43 * *$ & $.42 * *$ & $.43^{* *}$ & $.41 * *$ \\
\hline 5. CEBRACS: Total Score & $.47^{* * *}$ & $.30^{* * *}$ & $.51^{* *}$ & $.52 * *$ & $.52 * *$ & $.53^{* *}$ \\
\hline 6. CEBRACS: Before & $.49^{* * *}$ & $.31^{* *}$ & $.55^{* *}$ & $.56^{* * *}$ & $.58^{* * *}$ & $.56^{* *}$ \\
\hline 7. CEBRACS: During & $.47 * *$ & $.32 * *$ & $.50 * *$ & $.52^{* *}$ & $.45^{* *}$ & $.61 * *$ \\
\hline 8. CEBRACS: After & $.32 * *$ & $.25 * *$ & $.35 * *$ & $.36 * *$ & $.34 *$ & $.31^{*}$ \\
\hline
\end{tabular}

Binge drinking in relation to the AUDIT was identically correlated for both men and women (both $r=.79, p<.001$ ). Women had a stronger correlation with binge drinking and alcohol frequency $(r=.83, p<.001)$ than men $(r=.77, p$ $<.001)$, but male binge drinking had stronger correlations with alcohol dependence $(r=.78, p<.001)$ and alcohol-related problems $(r=.79, p<.001)$ than female binge drinking $(r=.72, p<.001, r=.68, p<.001$, respectively). Female binge drinking had a stronger correlation with compensatory behaviors during a drinking session than males, while male binge drinking was slightly stronger than female binge drinking before imbibing alcohol.

Opioid use was significantly, negatively correlated with the alcohol frequency $(r=-.22, p<.05)$ and dependence $(r=$ $-.32, p<.001)$ subscales of the AUDIT, but not the alcohol-related problems subscale. Opioid use did not have a significant relationship with any aspect of compensatory eating behaviors in relation to alcohol use. However, morphine was the only opioid to have statistically significant relationships with the CEBRACS alcohol effects $(r=-.33)$, diet and exercise $(r=-.38)$, and restrictive eating $(r=-.31)$, subscales (all $p<.001)$ as well as the CEBRACS total score $(r=$ $-.32, p<.001)$, but not with the bulimic subscale of the CEBRACS. Similarly, specific morphine use was the only opioid to have a significant, negative relationship with the alcohol frequency $(r=-.36, p<.05)$ and alcohol dependence $(\mathrm{r}=-.39, p<.001)$ subscales as well as the AUDIT total scores $(r=-.32, p<.05)$, but not the alcohol-related problems subscale.

Table 3. Correlation Matrix of Opioid Relationships

\begin{tabular}{|c|c|c|c|c|c|c|c|c|}
\hline Opioids & 1 & 2 & 3 & 4 & 5 & 6 & 7 & 8 \\
\hline 1. Morphine & 1.000 & & & & & & & \\
\hline 2. Fentanyl & $.50 * *$ & 1.000 & & & & & & \\
\hline 3.Hydrocodone & $.62 * *$ & $.43 * *$ & 1.000 & & & & & \\
\hline 4.Hydromorphone & $.67 * *$ & $.57 * *$ & $.52 * *$ & 1.000 & & & & \\
\hline 5. Oxycodone & $.69 * *$ & $.56^{* *}$ & $.67 * *$ & $.67 * *$ & 1.000 & & & \\
\hline 6. Methadone & $.67 * *$ & $.41^{* *}$ & $.66^{* *}$ & $.63 * *$ & $.56^{* *}$ & 1.000 & & \\
\hline 7. Meperdine & $.39 * *$ & $.54 * *$ & $.34 * *$ & $.47 * *$ & $.39 * *$ & $.45^{* *}$ & 1.000 & \\
\hline 8. Heroin & $.70 * *$ & $.65^{* *}$ & $.55^{* *}$ & $.71 * *$ & $.60 * *$ & $.60 * *$ & $.48 * *$ & 1.000 \\
\hline
\end{tabular}

Note. $\mathrm{N}=77,{ }^{*} \mathrm{p}<.05$, two-tailed. $* * \mathrm{p}<.001$, two-tailed.

Opioid Use Relationships. A follow-up Kendall's tau $b$ was conducted to examine specific opioid correlations with 
other opioids in an effort to explore potential comorbidity among opioid use. The largest correlation was between heroin and hydromorphone (see Table 3), followed by heroin and morphine. Notably, heroin had the strongest correlations with other opioids at an alpha of $p<.001$, followed by hydromorphone. Meperidine and fentanyl displayed the weakest relationships with other opioids.

Two follow-up Kendall's tau $b$ analyses were conducted to discern how opioid relationships differed between males and females. For males, the relationship between oxycodone and morphine was strongest $(r=.80, p<.001)$ followed by heroin and fentanyl $(r=.77, p<.001)$, while the relationship between meperidine and hydrocodone was the weakest $(r$ $=.40, p<.05)$. For females, the relationship between heroin and hydromorphone was the strongest $(r=.78, p<.001)$ followed by heroin and morphine $(r=.74, p<.001)$, and morphine and hydromorphone $(r=.74, p<.001)$. There were statistically significant relationships between all opioids for males, but for females the relationships between meperidine and morphine, hydrocodone, and oxycodone were non-significant.

\section{Hypothesis 2}

A moderated multiple regression analysis with a bootstrap of 1,000 replicates was used with the SPSS macro PROCESS (Hayes, 2012) to assess if opioid use displayed any moderating effects between alcohol frequency and compensatory eating behaviors in relation to alcohol consumption. Opioid use did not have a significant moderating effect between alcohol frequency and the CEBRACS $(b=.84, t(73)=.43, p=.67)$. A follow-up multiple moderation analysis was conducted to assess possible moderating effects for each specific opioid. The general item of opioid use $(b=4.87, t(71)$ $=1.49, p=.14)$ as well as morphine use $(b=-6.02, t(71)=-1.83, p=.07)$ were not statistically significant moderators between alcohol frequency and compensatory eating behaviors in relation to alcohol, but the results had indicated that morphine was the specific opioid closest to statistical significance. This was noteworthy as the finding was congruent with the previous correlation analysis where morphine was the only opioid to have significant relationships with all but the bulimic subscale of the CEBRACS.

Based on these findings, a forced hierarchical multiple regression was conducted to further examine the interaction effects of the three most common opioids in the sample (i.e. hydrocodone, morphine, and oxycodone), alcohol frequency, and reported opioid use on CEBRACS total scores. As expected, the frequency with which a person drinks is significantly predictive of their compensatory eating behaviors in relation to alcohol. Notably, morphine, hydrocodone, oxycodone, and general opioid use explained an additional $37 \%$ of the variance in compensatory eating behaviors in relation to alcohol consumption when alcohol frequency was controlled $\left(F(4,71)=2.87, p<.05, R^{2}=.37\right)$. Alcohol frequency and the use of morphine were each significant predictors of compensatory eating behaviors in relation to alcohol, but hydrocodone, oxycodone, and general opioid use were not (see Table 4). Saliently, morphine use resulted in a negative beta weight, suggesting that morphine use maintained a unique negative effect with regard to CEBRACS-measured behaviors.

Table 4. The Negative Moderating Effect of Morphine on AUDIT Frequency in Relation to CEBRACS Total Scores

\begin{tabular}{|c|c|c|c|c|c|c|c|c|c|}
\hline & & $\bar{B}$ & S. E. & $\bar{\beta}$ & $t$ & $p$ & $R$ & $R^{2}$ & $\Delta R^{2}$ \\
\hline \multirow{3}{*}{1} & (CEBRACS Total Score) & 21.09 & 3.60 & & 5.86 & .000 & & & \\
\hline & Drinking Frequency & 2.33 & .44 & .52 & 5.23 & .000 & .52 & .27 & .27 \\
\hline & (CEBRACS Total Score) & 23.19 & 5.38 & & 4.31 & .000 & & & \\
\hline \multirow[t]{5}{*}{2} & Drinking Frequency & 1.73 & .51 & .38 & 3.37 & .001 & .61 & .37 & .10 \\
\hline & Opioid Use & 9.88 & 6.86 & .25 & 1.44 & .154 & & & \\
\hline & Oxycodone & 5.45 & 5.53 & .15 & .99 & .33 & & & \\
\hline & Hydrocodone & 3.79 & 6.29 & .10 & 60 & .55 & & & \\
\hline & Morphine & -19.01 & 6.05 & -.51 & -3.14 & .002 & & & \\
\hline
\end{tabular}

Hypothesis 3

A Mann-Whitney $U$ test was used to assess potential differences between males and females with regard to compensatory eating behaviors in relation to alcohol consumption. Overall, men $(M d n=27.00)$ and women $(M d n=$ 33.00) did not differ significantly on the CEBRACS, although women ranked higher than men $(U=678.00, z=-.68, n s$, $r=.08)$. The rankings for the CEBRACS were highest within the Alcohol Effects subscale for both men $(M d n=12.00)$ and women $(M d n=15.00)$ despite a lack of gender difference for total CEBRACS scores $(U=659.50, z=-.84, n s, r$ $=.10)$. Notably, males $(M=39.34)$ had a mean rank which was slightly higher than females $(M=38.64)$ on the Bulimic Behaviors subscale of the CEBRACS.

A subsequent Mann-Whitney $U$ test was used to assess potential gender differences in the AUDIT to ascertain if significant gender similarities were isolated to the CEBRACS or also evident in behaviors displaying drinking dependence, frequency, and recognition of negative effects. This procedure revealed that men $(M d n=22.00)$ did not differ significantly from women $(M d n=23.00)$ on the AUDIT $(U=736.00, z=-.04, n s, r=.005)$. Based on these findings, it was concluded that men and women did not differ significantly with regard to compensatory eating 
behaviors in relation to alcohol consumption, and follow-up analysis indicated that they did not significantly differ with regard to alcohol use.

\section{Hypothesis 4}

A linear regression analysis was used to test how well binge drinking could predict compensatory eating behaviors in relation to alcohol. In both males $(b=.50, t(38)=3.59, p<.001)$ and females $(b=.60, t(35)=4.46, p<.001)$ binge drinking was a significant predictor of alcohol-related compensatory eating behaviors. Notably, binge drinking accounted for a larger proportion of the variance for women $\left(F(1,35)=19.86, p<.001, R^{2}=.36\right)$ than men $(F(1,38)=$ $\left.12.88, p<.001, R^{2}=.25\right)$. Specifically, binge drinking was best at predicting the Alcohol Effects subscale in both males $\left(F(1,38)=17.65, p<.001, R^{2}=.32\right)$ and females $\left(F(1,35)=39.99, p<.001, R^{2}=.53\right)$ accounting for $53 \%$ of the variance for women and $32 \%$ for men.

\section{Discussion}

The purposes of this study were to: (a) explore possible relationships between opioid use, alcohol use, and compensatory eating behaviors, (b) assess if opioid use moderates a relationship between the frequency of alcohol use and compensatory eating behaviors in relation to alcohol consumption, (c) examine gender differences with regard to compensatory eating behaviors in relation to alcohol consumption, and (d) use the CEBRACS in a clinical sample. This is the first known study to incorporate the CEBRACS with a clinical sample of participants. As opioid (ab) use and specifically heroin use has become increasingly salient problems in the United States, it is warranted to further examine opioid (ab)use in connection with various other constructs of interest such as disordered eating, drinking, and caloric restriction.

It should be noted that gender became a covariate of immense interest throughout the study as it was logical to examine the ways in which males and females differed across psychoactive substance use and compensatory eating behaviors in relation to alcohol consumption. Therefore, follow-up and additional analyses often encompassed gender comparisons. This emphasis was influenced by previous research stressing the importance of gender-specific treatment for assessing and treating psychoactive substance abuse in the Midwest (Boyd, 2014) and throughout the United States (Barrett, 2013; Ceylan-Isik, McBride, \& Ren, 2010; Tull, Gratz, Coffey, Weiss, \& McDermott, 2013). The following provides interpretation of the results while also including possible strategies for future research.

\section{Hypothesis 1}

The first hypothesis was exploratory in nature and lead to some meaningful relationships between study variables. All of the subscales of the CEBRACS except for bulimia were significantly and positively related to each of the AUDIT subscales and binge drinking behaviors. Binge drinking and alcohol frequency were correlates used in the standardization of the CEBRACS (see Rahal et al., 2012), but to date the CEBRACS has not been used in concomitance with the AUDIT and opioid use assessment in a clinical sample. The AUDIT consistently had a significant relationship with the CEBRACS which may have added meaningful support for the translation and convergent validity of the CEBRACS even though psychometric support for the CEBRACS was not an intent of the study. Generally, alcohol frequency and alcohol-related problems were more apparent issues than alcohol dependence as reported by the current sample.

The fact the bulimic behaviors maintained the weakest relationship across all study variables is congruent with past research using the CEBRACS (see Allen, 2014), but also disparate with most research on alcohol and eating disorder comorbidity (Trace et al., 2013; Chernoff et al., 2015). As advantageous as the utilization of a clinical sample was to the study, the clinical characteristics of the sample may have posed problems with regard to this finding. There is pertinent research from Jonas and Gold (1987) suggesting that opioids have an antagonistic effect on eating disorders specifically with regard to the effect of naltrexone and bulimic behaviors by reducing binge/purge symptomology. Similarly, other researchers have formulated compelling arguments for the treatment of eating disorders such as anorexia nervosa, bulimia nervosa, and binge eating disorder with opioids like nalmefene (Rovai et al., 2014) which is an argument based on the findings regarding opioids, alcohol, and disordered eating reward stimuli aforementioned in the introduction.

It is possible that opioid use had diminished symptoms of disorded eating pathology. Therefore, a specific lack of significance with regard to bulimic behaviors as measured by the CEBRACS may be due to a majority of participants (68\%) having reported recent opioid use. The comorbidity of alcohol use and eating disorders has been fairly well-established (see Jones, Cheshire, \& Moorhouse, 1980), but the literature would benefit from further research on opioid use and eating disorders as well as the possible clinical significance of opioids in relation to eating disorder symptomology.

Male binge and general drinking behaviors had a stronger relationship with bulimia than female binge drinking, and men scored slightly higher on the Bulimic Behavior subscale than women. This finding was surprising and in contrast with previous research (i.e. Krahn et al., 2005; Keski - Rahkonen, 2013). These correlations were noteworthy as women usually display more bulimic behaviors than men (Anderson \& Bulik, 2004). However, more women reported opioid 
use than men, and if the antagonistic effects of opioids on disordered eating are valid then these antagonistic effects may be partially responsible for the results. It is also possible that the men within the current study used alcohol in concomitance with a type of eating disorder, namely bulimia, to a greater degree than women. Further research into the interactions between opioids and disordered eating with the inclusion of gender would be necessary to support this assertion.

This study incorporated a temporal analysis by transforming the CEBRACS into three separate (before, during, and after drinking) variables and examining their relationships. While all AUDIT subscales were statistically significant ( $p$ $<.001)$ with the "after drinking behaviors" they showed marked weakness in correlational strength. Similarly, both male and female binge drinking decreased substantially from the "before" and "during" behaviors and also became less significant throughout the course of drinking $(p<.001-p<.05)$. A majority of the participants reported compensatory behaviors undertaken in the "before" stage of drinking and scored higher on the Alcohol Effects subscale than other subscales of the CEBRACS.

Opioid Use and Opioid Relationships. The use of opioids within the last year did not have a significant relationship with the CEBRACS or any of its subscales. However, morphine was the only specific opioid to have statistically significant, negative relationships with all but the Bulimic subscale of the CEBRACS. This is a highly noteworthy finding based on current neuropsychological, disordered eating, and substance use research which may be indicative of the aforementioned research regarding opioid use and eating disorder comorbidity. However, the CEBRACS as a measure does not specifically address bulimia or anorexia nervosa in clinically diagnostic terms nor were opioid antagonists such as naltrexone or nalmefene specifically assessed within the current study. Although the salience of morphine is compelling, it is not possible to draw a definitive conclusion as to why this specific opioid maintained a largely significant negative relationship with the CEBRACS. Therefore, just as general research into opioid use, alcohol use, and comorbid disordered eating is warranted, the specific use of the CEBRACS in concomitance with other diagnostic tools (e.g. criteria from the Diagnostic and Statistical Manual for Mental Health Disorders) should be of similar interest.

Hydrocodone was the most widely used opioid in the current sample followed by oxycodone and morphine. This prevalence was not surprising as hydrocodone and oxycodone are the most commonly prescribed drugs in the United States (Walsh, Nuzzo, Lofwall, \& Holtman, 2008; Kolodny et al., 2015). Heroin had the strongest relationships with other opioids and heroin's strong association with other study opioids are likely supportive of findings from previous studies indicating that prescription opioid users are shifting to heroin as prescription drugs become less available or harder to abuse (Muhuri, Gfroerer, \& Davies, 2013) and that more people are turning to prescription drugs when heroin is geographically or monetarily unavailable to them (Dart et al., 2015). The relationship between oxycodone and morphine was strongest followed by heroin and hydromorphone and then heroin and fentanyl. The rationale for these relationships is unclear, but may also be dependent upon availability and affordability. It may be important to note that morphine and oxycodone are consecutive in terms of potency with the latter being the most potent (Zacny \& Lichtor, 2008). Therefore, the proximal relationship in experienced drug effects may be relative to the observed relationship in the current study. Saliently, intravenous administration of oxycodone and fentanyl has been known to produce prototypical opioid-like effects that can be experientially and biophysically similar to heroin, and therefore oxycodone and fentanyl maintain comparable abuse potential (Comer, Sullivan, Whittington, Vosburg, \& Kowalczyk, 2008).

\section{Hypothesis 2}

Opioid use was not a significant moderator between alcohol use and compensatory eating behaviors in relation to alcohol consumption. It was hypothesized that opioid use might have played a moderating role between alcohol use and compensatory behaviors because of the constipating effect of opioids (Bruera et al., 1994) and the laxative effects of alcohol. Specifically, moderate-to-heavy alcohol use can have a concomitant diuretic and laxative effect (Reddy, Singal, \& Powell, 2010) and opioids can conversely have a constipating effect (Camilleri, et al., 2014). Operating under the assumption that individuals would engage in compensatory behaviors including the use of laxatives and diuretics, it was hypothesized that opioid use might have been used to better regulate any exacerbated gastrointestinal effects incurred from simultaneous supplement and alcohol use. However, diuretic and laxative use was relatively sparse within sample as only $3.9 \%$ reported "sometimes" taking diuretics and $7.8 \%$ reported "sometimes" taking laxatives before drinking alcohol.

A follow-up forced regression analysis with the top three commonly used opioids and controlling for alcohol frequency yielded additional results of interest concerning morphine. Participants who reported morphine use were less likely to engage in alcohol related compensatory eating behaviors and therefore presented a potentially unique dynamic between morphine and compensatory eating behaviors which was not found for other opioids or general opioid use. A possible explanation for this result may be in the relationship between endogenous morphine production and eating disorder symptomology. Endogenous morphine was first discovered in animals during the 1970's and later confirmed in humans 
during the turn of the century (see Poeaknapo, Schmidt, Brandsch, Dräger, \& Zenk, 2004). Neuropsychological researchers have identified high levels of endogenous morphine in bulimic and anorectic patients as compared to controls and have posited a biological predisposition toward disordered eating behaviors based on these neurobiological findings (Marrazzi, Luby, KinzieMunjal, \& Spector, 1997; Marazzi et al., 1990). It may be that the significantly negative association between morphine and most CEBRACS behaviors is linked to these results insofar as the participants in the current study may have higher levels of endogenous morphine and are therefore unlikely or disinterred in exogenous morphine use. However, thorough neuropsychological testing would be necessary to add credence to this assertion. Nevertheless, there was a compelling negative association between the CEBRACS and morphine that garners further investigation.

\section{Hypothesis 3}

The third hypothesis was not supported and there were no significant differences between men and women with regard to the CEBRACS or the AUDIT. This finding is congruent with previous alcohol use research (see NIAAA, 2016; Wilsnack, Vogeltanz, Wilsnack, \& Harris, 2000) as well as CEBRACS research (Rahal at el., 2012). However, men reported greater alcohol frequency and dependence while women reported higher scores on the alcohol problems subscale of the AUDIT which is also congruent with past research (Hoffman, Sklar, \& Nixon, 2015; Nixon, Prather, \& Lewis, 2014). It was originally hypothesized that women might exhibit more compensatory behaviors in relation to alcohol consumption even if the frequency with which both genders consume alcohol is not significantly different from one another because women have a greater historical prevalence of disordered eating habits when compared to men (see Fattore, Melis, Fadda, \& Fratta, 2014 for review). Howe ver, this was not the case and male binge drinking was actually better correlated with the Bulimia subscale of the CEBRACS in the current sample. This finding is not entirely surprising as male bulimia nervosa often manifests and shares similar comorbidity with bulimia nervosa in females (Anderson \& Bulik, 2004). Although beyond the scope of the current study, this finding possibly lends credence to the growing body of literature submitting that male body image and eating disorders are largely underdiagnosed and unrecognized (McFarland \& Kaminski, 2009; Strother, Lemberg, Stanford, \& Turberville, 2012).

\section{Hypothesis 4}

Binge drinking proved to be a significant predictor of compensatory eating behaviors in relation to alcohol consumption for both genders. Drinking frequency was logically expected to be a significant predictor of CEBRACS behaviors, simply because the more often a person drinks the more likely they are to engage in compensatory behaviors related to drinking. Therefore, the specific behavior of binge drinking was assessed as a way to expand this notion by analyzing how excessive alcohol consumption relates to compensatory behaviors. Notably, binge drinking was a better predictor for women than men, even though more men $(n=35)$ reported binge drinking than women $(n=27)$. For both genders, binge drinking best predicted the Alcohol Effects subscale of the CEBRACS, which may allude to a greater preoccupation to intensify the effects of alcohol as opposed to a central preoccupation with body image concerns.

Indeed, participants tended to respond more favorably to CEBRACS behaviors that would bolster the effects of alcohol rather than behaviors intended to protect against weight gain. For women, binge drinking was able to predict all aspects of the CEBRACS save for the Bulimic subscale, while male binge drinking was a significant predictor of all CEBRACS subscales. Numerous factors have been shown to play prominent roles in possible male endorsement of bulimic behaviors such as trait urgency and learned expectancies (Schaumberg \& Earleywine, 2013) weight and body image dissatisfaction (Anderson \& Bulik, 2004), sport participation (Blouin \& Goldfield, 1995), pursuits of muscularity (Ricciardelli \& McCabe, 2004), and muscle dysmorphia (Pope, Phillips, \& Olivardia, 2000).

If an overarching goal for the participants was the maintenance of weight and optimal body image, then it was anticipated that perhaps binge drinking would appear antithetical to that goal considering the copious consumption of empty calories. However, the comorbidity of male and female alcohol use in relation to eating disorders is typically similar (Rush, Curry, \& Looney, 2015), and binge eating and binge drinking have been found to be statistically related in past literature (see Ferriter, \& Ray, 2011; for review). Therefore it was noteworthy that binge drinking as well as drinking frequency were both significant predictors of total CEBRACS scores for both males and females.

\section{Limitations}

A prominent limitation to the current study is that it is cross-sectional in nature and no causal inferences can be made about the results. A second limitation regards the CEBRACS insofar as that the instrument only alludes to underlying body image disturbances, anorectic behaviors, and bulimia nervosa. The inclusion of specific body dysmorphic and disordered eating criteria could have benefitted the study, but were omitted to keep the battery of questionnaires manageable for participants. Lastly, neuropsychological testing in the forms of blood tests and brain imaging techniques would have been feasible considering the substance use component of the study, but these approaches were not possible given the resources of the testing facility. 


\section{Conclusion}

The results of this study are unique in that this was the first instance where the CEBRACS had been administered to a clinical sample of inpatients in an addiction treatment facility. Morphine was the only opioid to have a significant negative relationship with all aspects of the CEBRACS save for bulimia, which may have implications for body image, alcohol use, and opioid use disorders. Binge drinking proved to be an excellent predictor of CEBRACS behaviors, and therefore the quantity a person drinks is comparatively integral to the frequency with which a person drinks with regard to compensatory eating behaviors in relation to alcohol use. Also, men displayed more bulimic behaviors than women in the current sample, and it is possible that males with co-occurring substance use disorders may in fact share a similar prevalence of disordered eating with their female counterparts. Predispositional and comorbid factors are of salient interest to adequately examine any theory on gender, substance use, and eating disorder interrelationships or influences. Furthermore, the results from this study support that individual dietary habits do fluctuate before, during, and after alcohol consumption, and that understanding the goals of the individual is crucial in discerning substance use or disordered eating preoccupations on a casewise basis.

\section{References}

Allen, J. P., Litten, R. Z., Fertig, J. B., \& Babor, T. (1997). A review of research on the Alcohol UseDisorders Identification Test (AUDIT). Alcoholism: Clinical and Experimental Research, 21(4), 613-619. https://doi.org/10.1111/j.1530-0277.1997.tb03811.x

Allen, R. (2014). Compensatory eating behaviors and alcohol consumption. Presented as a thesis defense at Auburn University. Retrieved from: https://etd.auburn.edu/handle/10415/4137

American Psychiatric Association. (2013). Diagnostic and statistical manual of mental disorders (5th ed.). Arlington, VA: American Psychiatric Publishing. https://doi.org/10.1176/appi.books.9780890425596

Anderson, C. B., \& Bulik, C. M. (2004) Gender differences in compensatory behaviors, weight and shape salience, and drive for thinness. Eating Behaviors, 5(1), 1-11. https://doi.org/10.1016/j.eatbeh.2003.07.001

Anderson, P., Cremona, A., Paton, A., Turner, C., \& Wallace, P. (1993). The risk of alcohol. Addiction, 88(11), 1493-1508. https://doi.org/10.1111/j.1360-0443.1993.tb03135.x

Babor, T. F., Higgins-Biddle, J. C., Saunders, J. B., \& Monteiro, M. G. (2001). The alcohol use disorders identification test: Guidelines for use in primary care (2nd ed.). Retrieved from: http://pftp.paho.org/Public/NMH/Alcohol/Cartagena/Articulos\%20USB/AuditBro-3.pdf?Mobile=1\&Source=\%2F _layouts\%2Fmobile\%2Fview.aspx\%3FList\%3De0923874-ac8b-4798-b0ae-be309b53f0b8\%26View\%3Db9b59ee1 -e24f-4a75-8826-6b6128274b00\%26RootFolder\%3D\%252FPublic\%252FNMH\%252FAlcohol\%252FCaagena\%2 52FArticulos\%2520USB\%26CurrentPage\%3D1

Barrett, B. (2013, November). Substance use reductions among female offenders participating in a gender-specific drug court intervention for prescription drug abusers: Does age matter? Presented at the 141st APHA Annual Meeting and Exposition (November 2-November 6, 2013).

Birnbaum, H. G., White, A. G., Schiller, M., Waldman, T., Cleveland, J. M., \& Roland, C. L. (2011). Societal costs of prescription opioid abuse, dependence, and misuse in the United States. Pain Medicine, 12(4), 657-667. https://doi.org/10.1111/j.1526-4637.2011.01075.x

Blouin, A. G., \& Goldfield, G. S. (1995). Body image and steroid use in male bodybuilders. International Journal of Eating Disorders, 18, 159-165.

https://doi.org/10.1002/1098-108X(199509)18:2<159::AID-EAT2260180208>3.0.CO;2-3

Bohn, M. J., Babor, T. F., \& Kranzler, H. R. (1995). The Alcohol Use Disorders Identification Test (AUDIT): Validation of a screening instrument for use in medical settings. Journal of Studies on Alcohol, 56(4), 423-432. https://doi.org/10.15288/jsa.1995.56.423

Boyd, C. J. (2014). Race/ethnicity and gender differences in drug use and abuse among college students. 21st Century research on drugs and ethnicity: Studies Supported by the National Institute on Drug Abuse, 6(2), 75-95.

Bruera, E., Suarez-Almazor, M., Velasco, A., Bertolino, M., MacDonald, S. M., \& Hanson, J. (1994). The assessment of constipation in terminal cancer patients admitted to a palliative care unit: A retrospective review. Journal of Pain and Symptom Management, 9(8), 515-519. https://doi.org/10.1016/0885-3924(94)90113-9

Bulik, C. M., Klump, K. L., Thornton, L., Kaplan, A. S., Devlin, B., Fichter, M. M., ... Mitchell, J. E. (2004). Alcohol use disorder comorbidity in eating disorders: a multicenter study. Journal of Clinical Psychiatry, 65(7), 1000-1006. https://doi.org/10.4088/JCP.v65n0718

Burke, S. C., Cremeens, J., Vail-Smith, K., \& Woolsey, C. (2010). Drunkorexia: Calorie restriction prior to alcohol 
consumption among college freshman. Journal of Alcohol and Drug Education, 54(2), 17-34.

Camilleri, M., Drossman, D. A., Becker, G., Webster, L. R., Davies, A. N., \& Mawe, G. M. (2014). Emerging treatments in neurogastroenterology: A multidisciplinary working group consensus statement on opioid - induced constipation. Neurogastroenterology \& Motility, 26(10), 1386-1395. https://doi.org/10.1111/nmo.12417

Carr, K. D. (2002). Augmentation of drug reward by chronic food restriction: Behavioral evidence and underlying mechanisms. Physiology \& Behavior, 76(3), 353-364. https://doi.org/10.1016/S0031-9384(02)00759-X

Center for Behavioral Health Statistics and Quality. (2015). Behavioral health trends in the United States: Results from the 2014 National Survey on Drug Use and Health (HHS Publication No. SMA 15-4927, NSDUH Series H-50). Retrieved from http://www.samsha.gov/data/

Center on Addiction and Substance Abuse. (2003). Food for thought: Substance abuse and eating disorders. Retrieved from http://www.casacolumbia.org/addiction-research/reports/food-thought-substance-abuse-and-eating-disorders

Centers for Disease Control and Prevention (2013). Alcohol and public health: Alcohol-related disease impact (ARDI). Retrieved from:

http://nccd.cdc.gov/DPH_ARDI/Default/Report.aspx?T=AAM\&P=f6d7eda7-036e-4553-9968-9b17ffad620e\&R=d 7a9b303-48e9-4440-bf47 -070a4827e1fd\&M=AD96A9C1-285A-44D2-B76D-BA2AE037FC56\&F=\&D=

Centers for Disease Control and Prevention. (2016). Wide-ranging online data for epidemiologic research (WONDER). Atlanta, GA: CDC, National Center for Health Statistics. Retrieved from http://wonder.cdc.gov

Ceylan-Isik, A. F., McBride, S. M., \& Ren, J. (2010). Sex difference in alcoholism: Who is at a greater risk for development of alcoholic complication? Life sciences, 87(5), 133-138. https://doi.org/10.1016/j.1fs.2010.06.002

Chambers, R. A. (2008). Drunkorexia. Journal of Dual Diagnosis, 4(4), 414-416. https://doi.org/10.1080/15504260802086677

Chernoff, M. A., Grant, J. D., Bucholz, K. K., Agrawal, A., Lynskey, M. T., Madden, P. A., ... Duncan, A. E. (2015). Bulimic behaviors and early substance use. Alcoholism: Clinical and Experimental Research, 39(9), 1740-1748. https://doi.org/10.1111/acer.12829

Comer, S. D., Sullivan, M. A., Whittington, R. A., Vosburg, S. K., \& Kowalczyk, W. J. (2008). Abuse liability of prescription opioids compared to heroin in morphine-maintained heroin abusers. Neuropsychopharmacology, 33(5), 1179-1191. https://doi.org/10.1038/sj.npp.1301479

Dart, R. C., Surratt, H. L., Cicero, T. J., Parrino, M. W., Severtson, S. G., Bucher-Bartelson, B., .. Green, J. L. (2015). Trends in opioid analgesic abuse and mortality in the United States. New England Journal of Medicine, 372(3), 241-248. https://doi.org/10.1056/NEJMsa1406143

Dierks, A. (2014). A risky cocktail: An examination of Drunkorexia behaviors and alcohol consumption based on gender. Presented at The National Conference on Undergraduate Research, 2013.

Eisenberg, M. H., \& Fitz, C. C. (2014). "Drunkorexia": Exploring the who and why of a disturbing trend in college students' eating and drinking behaviors. Journal of American College Health, 62(8), 570-577. ttps://doi.org/10.1080/07448481.2014.947991

Fattore, L., Melis, M., Fadda, P., \& Fratta, W. (2014). Sex differences in addictive disorders. Frontiers in neuroendocrinology, 35(3), 272-284. https://doi.org/10.1016/j.yfrne.2014.04.003

Ferriter, C., \& Ray, L. A. (2011). Binge eating and binge drinking: An integrative review. Eating behaviors, 12(2), 99-107. https://doi.org/10.1016/j.eatbeh.2011.01.001

Fischer, S., Settles, R., Collins, B., Gunn, R., \& Smith, G. T. (2012). The role of negative urgency and expectancies in problem drinking and disordered eating: Testing a model of comorbidity in pathological and at-risk samples. Psychology of Addictive Behaviors, 26(1), 112. https://doi.org/10.1037/a0023460

Fleming, M. F., Balousek, S. L., Klessig, C. L., Mundt, M. P., \& Brown, D. D. (2007). Substance use disorders in a primary care sample receiving daily opioid therapy. The Journal of Pain, 8(7), 573-582. ttps://doi.org/10.1016/j.jpain.2007.02.432

Franko, D. L., Keshaviah, A., Eddy, K. T., Krishna, M., Davis, M. C., Keel, P. K., \& Herzog, D. B. (2013). A longitudinal investigation of mortality in anorexia nervosa and bulimia nervosa. American Journal of Psychiatry, 170(8), 917-925. https://doi.org/10.1176/appi.ajp.2013.12070868

Giles, S. M., Champion, H., Sutfin, E. L., McCoy, T. P., \& Wagoner K. (2009). Caloric restriction on drinking days: An examination of drinking consequences among college students. Journal of American College Health, 57(6), 
603-610. https://doi.org/10.3200/JACH.57.6.603-610

Gosnell, B. A., \& Levine, A. S. (2009). Reward systems and food intake: Role of opioids. International Journal of Obesity, 33, S54-S58. https://doi.org/10.1038/ijo.2009.73

Hart, C., \& Ksir, C. (2012). Drugs, society, and human behavior (15th Ed.). McGraw-Hill: Boston.

Hayes, A. F. (2012). PROCESS: A versatile computational tool for observed variable mediation, moderation, and conditional process modeling. Retrieved from http://www.afhayes.com/public/process2012.pdf

Herz, A. (1997). Endogenous opioid systems and alcohol addiction. Psychopharmacology, 129(2), 99-111. https://doi.org/10.1007/s002130050169

Hoffman, L. A., Sklar, A. L., \& Nixon, S. J. (2015). The effects of acute alcohol on psychomotor, set-shifting, and working memory performance in older men and women. Alcohol, 49(3), 185-191. https://doi.org/10.1016/j.alcohol.2015.02.001

Islam, M. M., Day, C. A., Conigrave, K. M., \& Topp, L. (2013). Self-perceived problem with alcohol use among opioid substitution treatment clients. Addictive Behaviors, 38(4), 2018-2021. https://doi.org/10.1016/j.addbeh.2012.12.001

Jamieson, S. (2004). Likert scales: How to (ab) use them. Medical Education, 38, 1212-1218. https://doi.org/10.1111/j.1365-2929.2004.02012.x

Jonas, J. M., \& Gold, M. S. (1987). Naltrexone treatment of bulimia: Clinical and theoretical findings linking eating disorders and substance abuse. Advanced Alcohol Substance Abuse, 7(1), 29-37. https://doi.org/10.1300/J251v07n01_03

Jones, D. A., Cheshire, N., \& Moorhouse, H. (1980). Anorexia nervosa, bulimia, and alcoholism. Anorexia Nervosa and Bulimic Disorders: Current Perspectives, 19, 377-380.

Kachadourian, L. K., Homish, G. G., Quigley, B. M., \& Leonard, K. E. (2012). Alcohol expectancies, alcohol use, and hostility as longitudinal predictors of alcohol-related aggression. Psychology of addictive behaviors, 26(3), 414-422. https://doi.org/10.1037/a0025842

Kerridge, B. T., Saha, T. D., Chou, S. P., Zhang, H., Jung, J., Ruan, W. J., \& Hasin, D. S. (2015). Gender and nonmedical prescription opioid use and DSM-5 nonmedical prescription opioid use disorder: Results from the National Epidemiologic Survey on Alcohol and Related Conditions-III. Drug and Alcohol Dependence, 156, 47-56. https://doi.org/10.1016/j.drugalcdep.2015.08.026

Kershaw, S. (2008, March). Starving themselves, cocktail in hand. New York Times. Retrieved from http://www.nytimes.com

Keski-Rahkonen, A., Raevuori, A., Bulik, C. M., Hoek, H. W., Sihvola, E., Kaprio, J., \& Rissanen, A. (2013). Depression and drive for thinness are associated with persistent bulimia nervosa in the community. European Eating Disorders Review, 21(2), 121-129. https://doi.org/10.1002/erv.2182

Kolodny, A., Courtwright, D. T., Hwang, C. S., Kreiner, P., Eadie, J. L., Clark, T. W., \& Alexander, G. C. (2015). The prescription opioid and heroin crisis: A public health approach to an epidemic of addiction. Annual Review of Public Health, 36, 559-574. https://doi.org/10.1146/annurev-publhealth-031914-122957

Krahn, D. D., Kurth, C. L., Gomberg, E., \& Drewnowski, A. (2005). Pathological dieting and alcohol use in college women - a continuum of behaviors. Eating behaviors, 6(1), 43-52. https://doi.org/10.1016/j.eatbeh.2004.08.004

Lieber, C. S. (1991). Hepatic, metabolic and toxic effects of ethanol: Update. Alcoholism: Clinical and Experimental Research, 15(4), 573-592. https://doi.org/10.1111/j.1530-0277.1991.tb00563.x

Lieber, C. S. (2003). Relationships between nutrition, alcohol use, and liver disease. Alcohol Research and Health, 27, 220-231.

Lingford-Hughes, A. R., Welch, S., Peters, L., \& Nutt, D. J. (2012). BAP updated guidelines: Evidence-based guidelines for the pharmacological management of substance abuse, harmful use, addiction and comorbidity: recommendations from BAP. Journal of Psychopharmacology, 26(7), 899-952. https://doi.org/10.1177/0269881112444324

Lipkus, I. (1991). The construction and preliminary validation of a global belief in a just world scale and the exploratory analysis of the multidimensional belief in a just world scale. Personality and Individual Differences, 12(11), 1171-1178. https://doi.org/10.1016/0191-8869(91)90081-L

Mancinelli, R. (2013). Gender differences in alcohol-related impairment: a critical review. Open Access Alcohol, 1(8). 
1- 6. https://doi.org/10.13172/2053-0285-1-1-598

Marrazzi, M. A., Luby, E. D., Kinzie, J., Munjal, I. D., \& Spector, S. (1997). Endogenous codeine and morphine in anorexia and bulimia nervosa. Life sciences, 60(20), 1741-1747. https://doi.org/10.1016/S0024-3205(97)00133-1

Marrazzi, M. A., Mullings-Britton, J., Stack, L., Powers, R. J., Lawhorn, J., Graham, V., ... Gunter, S. (1990). Atypical endogenous opioid systems in mice in relation to an auto-addiction opioid model of anorexia nervosa. Life sciences, 47(16), 1427-1435. https://doi.org/10.1016/0024-3205(90)90521-R

Martins, S. S., Fenton, M. C., Keyes, K. M., Blanco, C., Zhu, H., \& Storr, C. L. (2012). Mood and anxiety disorders and their association with non-medical prescription opioid use and prescription opioid-use disorder: Longitudinal evidence from the National Epidemiologic Study on Alcohol and Related Conditions. Psychological medicine, 42(06), 1261-1272. https://doi.org/10.1017/S0033291711002145

McFarland, M. B., \& Kaminski, P. L. (2009). Men, muscles, and mood: The relationship between self-concept, dysphoria, and body image disturbances. Eating Behaviors, 10(1), 68-70.

https://doi.org/10.1016/j.eatbeh.2008.10.007

Mercer, M. E., \& Holder, M. D. (1997). Food cravings, endogenous opioid peptides, and food intake: Areview. Appetite, 29(3), 325-352. https://doi.org/10.1006/appe.1997.0100

Muhuri, P. K., Gfroerer, J. C., \& Davies, M. C. (2013). Associations of nonmedical pain reliever use and initiation of heroin use in the United States. Center for Behavioral Health Statistics and Quality: Data Review, 1-17. Retrieved from http://www.samhsa.gov/data/2k13/DataReview/DR006/nonmedical-pain-reliever-use-2013.htm)

National Institute on Alcohol Abuse and Alcoholism. (1993). Eighth special report to the U.S. Congress on alcohol and health. Rockville, MD: U.S. Department of Health and Human Services.

National Institute on Alcohol Abuse and Alcoholism. (2016). Sex differences to become fundamental element of alcohol research at NIAAA. NIAAA Spectrum, 8(1), 1-3. Retrieved from:

http://www.spectrum.niaaa.nih.gov/features/features-01.html

National Institute on Drug Abuse. (2014). Prescription drug abuse: What are opioids? Retrieved from http://www.drugabuse.gov/publications/research-reports/prescription-drugs/opioids/what-are-opioids

Nixon, S, J., Prather, R., \& Lewis, B. (2014). Sex differences in alcohol-related neurobehavioral consequences. In E.V. Sullivan and A. Pfefferbaum (Eds.) Alcohol and the Nervous System: Handbook of Clinical Neurology 125, (pp. 253-272). https://doi.org/10.1016/b978-0-444-62619-6.00016-1

Ortega, R. O., Chapela, I. B., \& Santoncini, C. U. (2012). Disordered eating behaviors and binge drinking in female high-school students: The role of impulsivity. Salud Mental, 35(2), 83-89.

Parent, M. C. (2012). Handling item-level missing data: Simpler is just as good. The Counseling Psychologist, 41(4), 568-600. https://doi.org/10.1177/0011000012445176

Peralta, R. L. (2002). Alcohol use and the fear of weight gain in college: Reconciling two social norms. Gender Issues, 20(4), 23-42. https://doi.org/10.1007/s12147-002-0021-5

Poeaknapo, C., Schmidt, J., Brandsch, M., Dräger, B., \& Zenk, M. H. (2004). Endogenous formation of morphine in human cells. Proceedings of the National Academy of Sciences of the United States of America, 101(39), 14091-14096. https://doi.org/10.1073/pnas.0405430101

Pope, Jr., H. G., Phillips, K., \& Olivardia, R. (2000) The Adonis complex: The secret crisis of male body obsession New York: The Free Press.

Rahal, C. J., Bryant, J. B., Darkes, J., Menzel, J. E., \& Thompson, J. K. (2012). Development and validation of the compensatory eating and behaviors in response to alcohol consumption scale (CEBRACS). Eating Behaviors, 13(2), 83-87. https://doi.org/10.1016/j.eatbeh.2011.11.001

Reddy, N. K., Singal, A., \& Powell, D. W. (2010). Alcohol-Related Diarrhea. In Guandalini, S., \& Vazuri, H. (Eds.), Clinical Gastroenterology. (pp. 379-392). New York: NY, Humana Press. https://doi.org/10.1007/978-1-60761-183-7_22

Ricciardelli, L. A., \& McCabe, M. P. (2004). A biopsychosocial model of disordered eating and the pursuit of muscularity in adolescent boys. Psychological Bulletin, 130(2), 179-205.

https://doi.org/10.1037/0033-2909.130.2.179

Roszell, D. K., Calsyn, D. A., \& Chaney, E. F. (1986). Alcohol use and psychopathology in opioid addicts on methadone maintenance. The American Journal of Drug and Alcohol Abuse, 12(3), 269-278. 
https://doi.org/10.3109/00952998609007396

Rovai, L., Maremmani, A. G. I., Bacciardi, S., Rugani, F., Massimetti, E., Gazzarrini, D., ... Maremmani, I. (2014). The role of the opioid system in eating disorders: Perspectives for new treatment strategies. Heroin Addiction and Related Clinical Problems, 16(3), 15-34.

Rumpf, H. J., Hapke, U., Meyer, C., \& John, U. (2002). Screening for alcohol use disorders and at-risk drinking in the general population: Psychometric performance of three questionnaires. Alcohol and Alcoholism, 37(3), 261-268. https://doi.org/10.1093/alcalc/37.3.261

Rush, C. C., Curry, J. F., \& Looney, J. G. (2015). Alcohol expectancies and drinking behaviors among college students with disordered eating. Journal of American College Health, (just-accepted), 00-00.

Saunders, J. B., Aasland, O. G., Babor, T. F., De la Fuente, J. R., \& Grant, M. (1993). Development of the alcohol use disorders identification test (AUDIT): WHO collaborative project on early detection of persons with harmful alcohol consumption - II. Addiction, 88(6), 791-804. https://doi.org/10.1111/j.1360-0443.1993.tb02093.x

Schaumberg, K., \& Earleywine, M. (2013). Evaluating the acquired preparedness model for bulimic symptoms and problem drinking in male and female college students. Eating Behaviors, 14(1), 47-52. https://doi.org/10.1016/j.eatbeh.2012.10.012

Shield, K. D., Parry, C., and Rehm, J. (2013). Chronic diseases and conditions related to alcohol use. Alcohol Research: Current Reviews, 35(2) 155-177.

Strother, E., Lemberg, R., Stanford, S. C., \& Turberville, D. (2012). Eating disorders in men: Underdiagnosed, undertreated, and misunderstood. Eating Disorders, 20(5), 346-355. https://doi.org/10.1080/10640266.2012.715512

Substance Abuse and Mental Health Services Administration . 2014. National Survey on Drug Use and Health. Table 5.8A-Substance dependence or abuse in the past year among persons aged 18 or older, by demographic characteristics: Numbers in thousands, 2013 and 2014. Retrieved from: http://www.samhsa.gov/data/sites/default/files/NSDUH-DetTabs2014/NSDUH-DetTabs2014.htm\#tab5-8a

Substance Abuse and Mental Health Services Administration, Office of Applied Studies. (2007). Highlights for 2002 treatment episode data set. Retrieved from http://oas.samhsa.gov/TEDS2k7highlights/toc.cfm

Trace, S. E., Thornton, L. M., Baker, J. H., Root, T. L., Janson, L. E., Lichtenstein, P., ... Bulik, C. M. (2013). A behavioral-genetic investigation of bulimia nervosa and its relationship with alcohol use disorder. Psychiatry Research,208(3), 232-237. https://doi.org/10.1016/j.psychres.2013.04.030

Tull, M. T., Gratz, K. L., Coffey, S. F., Weiss, N. H., \& McDermott, M. J. (2013). Examining the interactive effect of posttraumatic stress disorder, distress tolerance, and gender on residential substance use disorder treatment retention. Psychology of Addictive Behaviors, 27(3), 763-773. https://doi.org/10.1037/a0029911

Walsh, S. L., Nuzzo, P. A., Lofwall, M. R., \& Holtman, J. R. (2008). The relative abuse liability of oral oxycodone, hydrocodone and hydromorphone assessed in prescription opioid abusers. Drug and Alcohol Dependence, 98(3), 191-202. https://doi.org/10.1016/j.drugalcdep.2008.05.007

Warner, M., Chen, L. H., \& Makuc, D. M. (2009). Increase in fatal poisonings involving opioid analgesics in the United States, 1999-2006. NCHS data brief, 22, 1-8.

White, A. (2004). What happened? Alcohol, memory black- outs, and the brain. National Institute on Alcohol Abuse and Alcoholism. Retrieved on from http://pubs. niaaa.nih.gov/publications/arh27-2/186-196.htm

Wilsnack, R. W., Vogeltanz, N. D., Wilsnack, S. C., \& Harris, T. R. (2000). Gender differences in alcohol consumption and adverse drinking consequences: Cross - cultural patterns. Addiction, 95(2), 251-265. https://doi.org/10.1046/j.1360-0443.2000.95225112.x

Zacny, J. P., \& Lichtor, S. A. (2008). Within-subject comparison of the psychopharmacological profiles of oral oxycodone and oral morphine in non-drug-abusing volunteers. Psychopharmacology, 196(1), 105-116. https://doi.org/10.1007/s00213-007-0937-2

\section{Copyrights}

Copyright for this article is retained by the author(s), with first publication rights granted to the journal.

This is an open-access article distributed under the terms and conditions of the Creative Commons Attribution license which permits unrestricted use, distribution, and reproduction in any medium, provided the original work is properly cited. 